\title{
Monsoon rains start to ease India's drought
}

\section{K. S. Jayaraman, New Delhi}

A heatwave that scorched most of India throughout May, killing more than 1,400 people, is finally abating with the arrival of the first monsoon rains last week.

In the southern state of Andhra Pradesh, where temperatures reached a record $51{ }^{\circ} \mathrm{C}$ late last month, the first heavy rain was expected this week. It was desperately needed, as all nine of the state's main reservoirs had either dried up or reached precariously low levels.

The state government has set up an expert panel, chaired by C. V. V. Bhadram, director of the Andhra Pradesh meteorological office in Hyderabad, to identify factors that contributed to the drought and to marshal a response to it.

Afew weeks ago, the Indian Meteorological Department (IMD) in New Delhi predicted a "normal" monsoon, using a new statistical model; the previous model led to wrong forecasts being made in 2002 (see Nature 418, 713; 2002). But the monsoon that arrived last week was weaker than normal, and hit the northeast of India, rather than the south coast.

Given the unreliability of the electricity supplyin many parts of India, the heatwave has wreaked havoc in hospitals and laboratories, many of which lack emergency generators to power air-conditioners and the refrigerators that store vaccines, reagents and chemicals.

Debi Sarkar, a biochemist working at the University of Delhi, points out that "most reagents used in India are imported

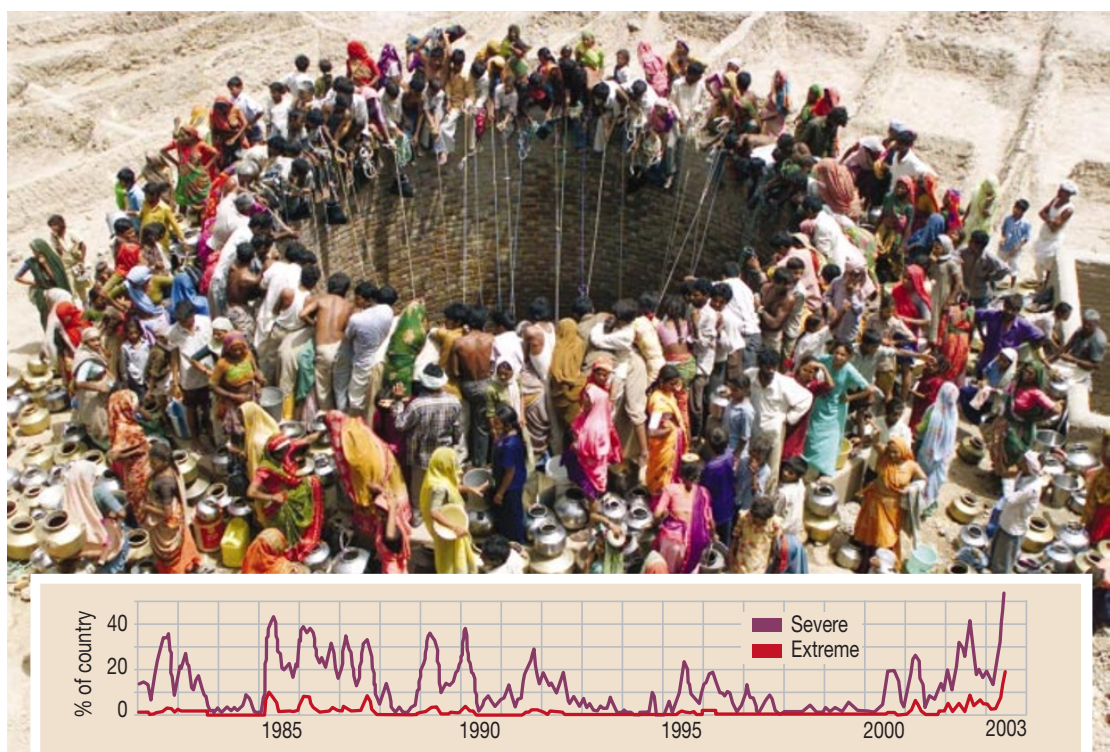

Scorched earth: India's worst drought for 20 years (inset) left people struggling to find water.

and kept in customs warehouses until they are collected". He predicts that many will have been degraded during the heatwave.

Subhash Arya, a vaccine expert at the Centre for Logistical Research and Innovation in New Delhi, says that India's polioeradication programme has been seriously set back by the weather.

India suffers from summer heatwaves from time to time, but according to several

\section{Quake triggers research expedition}

\section{Declan Butler, Paris}

Last month's earthquake in Algeria has prompted European researchers to mount a rare full-scale expedition to a region where political conflict over the past decade has sharply curtailed their fieldwork.

The earthquake, which struck the coast on 21 May, killing more than 2,000 people, prompted a French team of 30 Earth scientists to travel to Algeria to collaborate with colleagues at the Centre for Research in Astronomy, Astrophysics and Geophysics in Algiers. At 6.7 on the Richter scale, the earthquake was the worst in the region for more than 20 years.

The North African country lies on the southern side of the fault line at which the Eurasian and African tectonic plates meet, making it interesting to seismologists.

The researchers hope to obtain valuable data about that side of the fault, which has been neglected for more than a decade, says Alain Mauffret, a marine seismologist at the University of Pierre and Marie Curie in
Paris. Because of the conflict in Algeria, many Earth scientists have emigrated from the country, and research by outsiders has been difficult. "We can't send people there to have their throats cut," he says.

Mauffret, who helped to coordinate the mission for France's National Centre for Scientific Research (CNRS), says the need to collect data on the earthquake and its aftershocks made it vital to visit Algeria. The team has installed seismological monitoring equipment, and has measured more than 1,000 aftershocks since 21 May. Underwater stations are due to be added this week.

Satellite radar images are being used to measure ground deformation, and Global Positioning System stations are being deployed to detect ground movements. A hypothesis that the earthquake was triggered by an underwater landslide will be studied by a marine geophysics research group in August, organized by the CNRS and IFREMER, France's national marine research agency. data sources, this summer's drought is the worst for at least 20 years. The heatwave was fuelled by hot air flowing in from the Iranian desert - India normally receives a flow of cool, moist air from the Arabian Sea during May.

Satellite data (see graph) collected by the US National Oceanic and Atmospheric Administration (NOAA) show that more than two-thirds of India's vegetation is under either "severe" or "extreme" drought conditions, says Felix Kogan, a remotesensing specialist at NOAA's environmentaldata division at Camp Springs, Maryland.

An analysis by Uday Shankar De, a geophysicist and former research chief at the IMD in Pune, suggests that the number of hot, dry days in India during May and June has been increasing steadily over two decades. De and colleagues attribute the trend to global climate change.

"The increase in extreme events, such as the heatwave, is linked to global warming," claims J. Srinivasan, a professor of atmospheric sciences at the Indian Institute of Science in Bangalore.

The monsoon rains may not put an end to the crisis, researchers warn. Last year, the monsoon followed its normal pattern until late June and then faltered, resulting in a resumption of drought conditions. "After what happened last year, nobody will dare to make any prediction about the monsoon," says Srinivasan.

De takes a more sanguine approach. "The monsoon is like a train," he says. "If it arrives late at one station it doesn't matterit will make up for it before it arrives at the next one."

Additional reporting by Hannah Hoag in Washington. 